\title{
Correction to: Assessment of groundwater quality around municipal solid waste landfill by using Water Quality Index for groundwater resources and multivariate statistical technique: a case study of the landfill site, Qaem Shahr City, Iran
}

\author{
Hossein Najafi Saleh - Sima Valipoor - Asma Zarei • Mahmood Yousefi • \\ Farzaneh Baghal Asghari - Ali Akbar Mohammadi • Fazel Amiri • \\ Sahar Ghalehaskar • Amin Mousavi Khaneghah
}

Published online: 9 November 2020

(C) Springer Nature B.V. 2020

\section{Correction to:}

Environ Geochem Health (2020) 42:1305-1319

https://doi.org/10.1007/s10653-019-00417-0

In the original publication of the article, the name of the seventh author is incorrectly published as "Fazzel Amiri”.

The original article can be found online at https:// doi.org/10.1007/s10653-019-00417-0.

H. N. Saleh

Department of Environmental Health Engineering, School of Health, Torbat Heydariyeh University of Medical Sciences, Torbat Heydariyeh, Iran

\section{H. N. Saleh}

Health Sciences Research Center, Torbat Heydariyeh University of Medical Sciences, Torbat Heydariyeh, Iran

\section{S. Valipoor · F. Amiri}

Department of Environment, Bushehr Branch, Islamic Azad University, Bushehr, Iran

\section{A. Zarei}

Department of Environmental Health Engineering, School of Public Health, Gonabad University of Medical

Sciences, Gonabad, Iran

M. Yousefi · F. B. Asghari

Department of Environmental Health Engineering, School of Public Health, Tehran University of Medical Sciences, Tehran, Iran
The correct name of the author is "Fazel Amiri".

Publisher's Note Springer Nature remains neutral with regard to jurisdictional claims in published maps and institutional affiliations.
A. A. Mohammadi $(\square)$

Department of Environmental Health Engineering, Neyshabur University of Medical Sciences, Neyshabur, Iran

e-mail: mohammadi.eng73@gmail.com; mohammadia3@nums.ac.ir

S. Ghalehaskar

Instructor of Environmental Health Engineering, School of Health, Jiroft University of Medical Sciences, Jiroft, Iran

\footnotetext{
A. M. Khaneghah ( $\square)$

Department of Food Science, Faculty of Food Engineering, University of Campinas (UNICAMP), Rua Monteiro Lobato, 80, Caixa Postal: 6121, Campinas, São Paulo CEP: 13083-862, Brazil e-mail: mousavi@unicamp.br
} 